(C) 2021, The Authors. Published by Elsevier Inc. and Fass Inc. on behalf of the American Dairy Science Association ${ }^{\circledR}$. This is an open access article under the CC BY-NC-ND license (http://creativecommons.org/licenses/by-nc-nd/4.0/).

\title{
Economic impact of different strategies to use sex-sorted sperm for reproductive management in seasonal-calving, pasture-based dairy herds
}

\author{
E. Ruelle,* 다 L. Shalloo, (1) and S. T. Butler 두 \\ Teagasc, Animal and Grassland Research and Innovation Centre, Moorepark, Fermoy, Co. Cork, Ireland P61C996
}

\begin{abstract}
To maximize efficiency, profitability, and societal acceptance of modern dairy production, it is important to minimize the production of male dairy calves with poor beef merit. One solution involves using sex-sorted sperm (SS) to generate dairy replacements and breeding all other cows to an easy-calving, short-gestation bull with good beef merit. We used the Pasture Based Herd Dynamic Milk Model to investigate the effect of herd fertility and use of SS on farm net profit in a herd of 100 cows. This was completed by simulating herds with differing fertility performance (good, average, poor), and differing farm reproductive management [conventional semen (CONV) or SS with varying pregnancy per artificial insemination $(\mathrm{P} / \mathrm{AI})$ relative to $\mathrm{CONV}$ (i.e., relative $\mathrm{P} / \mathrm{AI} 100 \%, 85 \%$, and $70 \%$ )]. As an additional consideration, the method of allocating SS to cows was also examined. The first option used SS on random heifers and cows (S). The second option used SS on heifers and targeted high-fertility cows $\left(\mathrm{S}_{\text {Sel }}\right)$. The final option was similar to $\mathrm{S}_{\mathrm{Sel}}$, but used a fixed-time artificial insemination (AI) protocol to facilitate AI on the farm mating start date $\left(\mathrm{S}_{\text {Sync }}\right)$. For $\mathrm{CONV}$, dairy breed semen was used for AI until 50 animals were pregnant (50\% chance of a female calf), whereas for S, $\mathrm{S}_{\text {Sel }}$, or $\mathrm{S}_{\text {Sync }}$ the target number of animals successfully conceiving with SS was set at 28 (based on assumed $90 \%$ chance of a female calf from pregnancies derived from SS). Beef breed semen was used on all other dams. The results indicated that the biggest effect on farm net profit was not based on whether or not SS was used, but instead was most affected by the overall fertility performance of the herd. Total farm profit decreased by $10 \%$ between the good and average fertility herds, and decreased by a further $12 \%$ between the average and poor fertility herds. In almost all situations, when
\end{abstract}

Received January 13, 2021.

Accepted July 5, 2021.

*Corresponding author: elodie.ruelle@teagasc.ie the relative $\mathrm{P} / \mathrm{AI}$ with $\mathrm{SS}$ was $\geq 85 \%$, use of SS led to an overall increase of the farm net profit. There was an economic benefit of using either $\mathrm{S}_{\mathrm{Sel}}$ or $\mathrm{S}_{\mathrm{Sync}}$ compared with $\mathrm{S}$ for the average and poor fertility herds but not for the good fertility herd, highlighting an interaction between SS P/AI and overall herd fertility as well as management practices. If the relative $\mathrm{P} / \mathrm{AI}$ with $\mathrm{SS}$ was $<70 \%$, the use of SS led to a decrease in profitability in all simulations except for $\mathrm{S}_{\mathrm{Sync}}$, highlighting the importance of a good management strategy for use of SS. The findings in this study indicated that SS has significant potential to help facilitate greater integration between the dairy and beef production sectors, as well as increase farm profitability when used appropriately.

Key words: sex-sorted sperm, fertility, synchronization, economic impact, modeling

\section{INTRODUCTION}

The seasonality of calving in grass-based systems is associated with a seasonal glut in the births of dairy calves, with the male dairy calves having little economic value due to poor terminal beef characteristics as adults. In general, if these calves are sired by a beef breed bull, they are more valuable and easier to market. Hence, there is a requirement to simultaneously reduce the number of male dairy calves and increase the beef merit of all nonreplacement calves. The use of sex-sorted sperm (SS) as a strategy to reduce the number of male dairy calves also creates opportunities to improve beef characteristics by breeding more cows to beef breed bulls. This could increase the profitability of the industry as a whole, and also improve the sustainability of dairy and beef production and social acceptance by consumers. There are also management benefits for the dairy producer, including that all dairy heifer calf births occur at the start of the calving season to the dams that have the best genetics for dairy production (Butler et al., 2014). Sex-sorted sperm can also facilitate more rapid herd expansion if that is an objective, where greater numbers of replacement heifers are required (Hutchinson et al., 2013a,b). 
Flow cytometry was identified as a reliable method to distinguish populations of $\mathrm{X}$ - and Y-chromosomebearing sperm over 30 yr ago (Garner et al., 1983). Numerous refinements to the procedure have taken place to facilitate the commercial application of this technology (Vishwanath and Moreno, 2018) and now consistently produce a sex bias of approximately $90 \%$ in resulting offspring. However, there are the 2 following unfavorable effects of using SS: (1) the price premium for SS compared with conventional semen (CONV) straws and (2) reduced pregnancy per AI (P/AI) for SS compared with CONV (Oikawa et al., 2019; Drake et al., 2020; Maicas et al., 2020). Poor fertility with SS reflects a combination of damage to the sperm cells during the sorting process and fewer sperm cells per straw compared with CONV. The reduction in fertility performance is particularly problematic in seasonal dairy production systems where the importance of reproduction is greater than in year-round calving systems (Veerkamp et al., 2002; Shalloo et al., 2014). In seasonal pasture-based dairy production systems, excellent fertility is required to generate a compact calving period that coincides with the onset of spring pasture growth, enabling greater pasture utilization, longer lactations, increased milk production, and increased profitability. Hence, the majority of the herd must establish pregnancy early in the breeding season (Macmillan, 2002), and replacement heifers must enter the lactating herd at the start of the calving period.

The requirement that both excellent herd fertility performance is achieved and that nonreplacement offspring have good beef merit requires the available options to be evaluated from an economic perspective. The options available to dairy farmers are as follows:

- to continue using CONV to generate replacement female stock, and accepting that this strategy will result in approximately $50 \%$ of the resulting offspring being male dairy calves with poor beef merit;

- using SS across the herd, with an expected decline in herd phenotypic fertility performance (later average calving date, greater replacement rate);

- targeting use of SS on dams expected to have better inherent fertility performance (younger dams, better genetics for fertility, greater DIM at AI, greater BCS);

- targeting use of SS as outlined above, but with the inclusion of a synchronization program to facilitate AI with SS on the farm mating start date, thereby increasing the number of insemination opportunities within the breeding season, and thus mitigating the risk of reduced conception rates.
The objective of this paper was to investigate the economic impact of different SS usage strategies across a range of different scenarios in herds with varying fertility performance.

\section{MATERIALS AND METHODS}

\section{Model Presentation}

The Pasture Based Herd Dynamic Milk Model (PBHDM; Ruelle et al., 2015) model is a dynamic, stochastic agent-based model developed in $\mathrm{C}++$. The model simulates all of the main aspects of the life of an animal from birth to culling and death through several different submodels (Ruelle et al., 2016). The submodels of PBHDM include fertility, intake, animal growth, BCS change, and milk production. The model predicts the production of standard milk, fat, and protein yield. The simulation of the milk production per day is calculated based on an interaction between the energy and protein intake by the cow, BCS change, and the individual animal's potential milk yield. The model simulates each individual animal's intake at grazing, which is primarily dependent on the animal characteristics, but is also dependent on supplementation, grass availability, and quality. Grass growth is simulated with a daily time step that considers weather, management, and soil N dynamics (Ruelle et al., 2018).

The economic aspect of the model is based on the Moorepark Dairy Systems Model (MDSM; Shalloo et al., 2004) which has been fully integrated into the PBHDM since 2019. It is a stochastic budgetary simulation model with the objective of simulating pasture-based milk production systems across a range of sustainability and profitability indicators when changes are made to the farm. The model can test the effect of various institutional, economic, and technical changes within the Irish dairy industry. Examples where the model has been used include the development of an economic grass selection ranking index (McEvoy et al., 2011) or the evaluation of different expansion strategies across a 15-yr time horizon (McDonald et al., 2013). The model integrates animal inventory and valuation, milk production, feed requirement, land and labor utilization, and economic analysis. The model takes into account the variable costs (fertilizer, contractor charges, medical and veterinarian, AI, silage, and reseeding), fixed costs (machinery maintenance and running costs, farm maintenance, car, telephone, electricity, and insurance), and commodity prices (calf, milk, and cow). Outputs from the model include the detailed costs and receipts, profitability, as well as physical outputs such as the feed budget from the overall farm. 


\section{Genetic Inputs and Economic Breeding Index}

The economic breeding index (EBI) is the Irish breeding index, which was launched in February 2001 to identify genetically superior animals to increase profitability within Irish dairy herds (Veerkamp et al., $2002)$. The EBI is expressed as expected profit $(€)$ per lactation of the progeny of the animal in question, and the genetic merit values of the component traits are expressed as PTA. The inputs of the model are based on the EBI of 2018 (ICBF, 2017, 2018), which comprises the 7 following subindexes: production (34\% contribution to the overall EBI value), fertility [contribution of $34 \%$; calving interval in days $\left(\mathbf{P T A}_{\mathrm{CIV}}\right),-€ 12.59$; survival $\%$ (PTA $\left.\left.\mathbf{A}_{\text {long }}\right), € 12.01\right)$, calving (contribution of $10 \%$ ), beef (contribution of $8 \%$ ), maintenance (contribution of $6 \%$ ), management (contribution of $5 \%$ ), and health (contribution of $3 \%$ ). The production subindex is made up of 3 PTA, representing the milk yield [economic weight of $-€ 0.09 / \mathrm{kg}\left(\mathbf{P T A}_{\mathrm{MY}}\right)$, contribution of $8.9 \%$, protein yield [economic weight of $€ 5.58 / \mathrm{kg}\left(\right.$ PTA $\left._{\text {prot }}\right)$, contribution of $17.9 \%$ ], and fat yield [economic weight of $€ 2.08$ per $\mathrm{kg}\left(\mathbf{P T A}_{\text {fat }}\right)$, contribution of $7 \%$ ].

Genetic information used as inputs in the PBHDM model include PTA values for milk production traits $\left(\mathrm{PTA}_{\mathrm{MY}}, \mathrm{PTA}_{\text {prot }}\right.$, and $\mathrm{PTA}_{\text {fat }}$; Ruelle et al., 2019) and fertility traits $\left(\mathrm{PTA}_{\mathrm{CIV}}\right.$ and $\left.\mathrm{PTA}_{\text {long }}\right)$.

\section{Simulations}

Description of the Genetic Scenarios. Genetic merit for fertility traits was used in the simulations to generate categories of animals with good phenotypic fertility $\left(\mathrm{PTA}_{\mathrm{CIV}}=-1.25\right.$ and $\mathrm{PTA}_{\text {long }}=1.00$; average $\mathrm{P} / \mathrm{AI}$ at first insemination for cows was $60 \%$ within the model $)$, average phenotypic fertility $\left(\mathrm{PTA}_{\mathrm{CIV}}=2.00\right.$ and $\mathrm{PTA}_{\text {long }}=-1.50$; average $\mathrm{P} / \mathrm{AI}$ at first insemination for cows was $47 \%$ within the model), or poor phenotypic fertility $\left(\mathrm{PTA}_{\mathrm{CIV}}=4.00\right.$ and $\mathrm{PTA}_{\text {long }}=$ -3.00 ; average $\mathrm{P} / \mathrm{AI}$ at first insemination for cows was $37 \%$ within the model). As the model can only predict the percentage chance of AI success for cows, a fixed percentage AI success was set for heifers $(75 \%, 70 \%$, and $65 \%$ for the heifers with good, average, and poor fertility, respectively).

Description of the Insemination Scenarios. For each fertility scenario, the utilization of CONV or SS was simulated. In the CONV simulation, CONV semen was used until 50 animals were pregnant, and then beef breed semen was used for the remaining animals in the herd. For SS, 3 different scenarios were simulated, but in each scenario, dairy breed SS sperm straws were used until 28 cows became pregnant (90\% chance of female calf with SS). This was to ensure that the planned number of dairy heifer calves generated in all scenarios were approximately equal.

In the first sexed scenario (S), the first animals detected in estrus, irrespective of their likely fertility performance, were inseminated with SS until 28 animals were pregnant, and then beef semen was used for the remaining inseminations. In the second SS scenario $\left(\mathbf{S}_{\text {Sel }}\right)$, SS was used only on selected animals with high predicted chance of successful conception following insemination (calculated by the model). As heifers typically have greater P/AI than cows, SS was first prioritized for heifers. For lactating cows, the likelihood of pregnancy establishment was calculated by the model, assuming CONV was used at AI (based on BCS, DIM, and previous calving difficulty), and only those that were predicted to have a high likelihood of successful pregnancy establishment were inseminated with SS ( $\geq 63 \%, \geq 50 \%$, and $\geq 40 \%$ in the good, average, and poor herd fertility scenarios, respectively). This corresponded to a predicted mean increase of $3 \%$ in $\mathrm{P} / \mathrm{AI}$ at first insemination for each group. Once 28 selected animals (heifers or lactating cows) were pregnant, all remaining inseminations were with beef semen. The third sexed scenario was largely similar to $\mathrm{S}_{\mathrm{Sel}}$ in targeting animals with better potential fertility outcome, but included use of fixed-time AI synchronization $\left(\mathbf{S}_{\mathrm{Sync}}\right)$. In this scenario, the selected high-fertility dams (heifers and lactating cows) were synchronized to be inseminated with SS on the first day of the seasonal breeding period. The selection criteria for a cow to be synchronized was the same as the $\mathrm{S}_{\text {Sel }}$ scenario.

$P / A I$ Reduction Due to $S S$. A correction factor to account for reduced likelihood of successful pregnancy establishment for SS AI events was applied by assuming that the mean $\mathrm{P} / \mathrm{AI}$ for SS would be $85 \%$ of that achieved with CONV, which is in line with recent large field trials conducted in Ireland (Maicas et al., 2019, 2020; Drake et al., 2020). As there was considerable herd-to-herd variation in the $\mathrm{P} / \mathrm{AI}$ of $\mathrm{SS}$ relative to CONV in these field trials (Drake et al., 2020), scenarios with $100 \%$ relative $\mathrm{P} / \mathrm{AI}$ (i.e., no reduction in fertility) or $70 \%$ relative $\mathrm{P} / \mathrm{AI}$ (marked reduction in fertility) were also examined in the current study. For pregnancies that were successfully established, the probability of a female calf when using SS was set to 90\% (Vishwanath and Moreno, 2018). The price of conventional, sexed, and beef semen straws included in the model were $€ 18$, $€ 38$, and $€ 6$, respectively, with an additional flat rate $\mathrm{AI}$ service cost of $€ 7 /$ insemination. The cost of synchronization using a progesteroneOvsynch protocol (Drake et al., 2020) was €30/cow.

General Assumptions in Simulations. The simulations were performed based on a time series of weather data from the Moorepark weather sta- 
tion $\left(52^{\circ} 10^{\prime} 14.5^{\prime \prime} \mathrm{N}, 8^{\circ} 14^{\prime} 34.9^{\prime \prime} \mathrm{W}\right)$ over a 17 -yr period (2003-2019). Each simulation was run 1,000 times to avoid false results due to the stochasticity of the model related to probabilities for different variables (e.g., submission for AI, P/AI, death, and culling).

The size of the herd was fixed at 100 cows. Heifers not pregnant after the end of the breeding period were immediately sold for $€ 565$ based on current values. Cows not pregnant after the end of the breeding period were sold at dry off (d 348 of the year) for $€ 500$. If there were not enough gestating cows and heifers by December 31 to reach the minimal number of animals required for the subsequent year, replacement heifers were purchased for $€ 1,550$ (Shalloo et al., 2014) to maintain the herd size of 100 cows. To create this purchased heifer, a random existing gestating heifer from the farm was duplicated. Any parity 10 cow was culled on the December 31, irrespective of her gestation status, at the price of $€ 500$. If the total number of gestating animals was greater than the maximum number of animals allowed on the December 31, some gestating cows and heifers (but not those inseminated with SS) were sold for the price of $€ 1,000$ (industry consultation) and $€ 1,550$, respectively. Male dairy calves and crossbreed beef calves were sold at 3 wk of age with a value differential of $€ 150$ (€0 and $€ 150$, respectively).

All costs, including silage making costs and fertilizer costs, were included in the model based on the current (2020) costs in Ireland, and were generated based on industry consultation. These costs included concentrate at $€ 280 / t$, fertilizer nitrogen at $€ 200 / t$, and silage contractor costs at $€ 100$ per ha.

The grazing period was fixed for each year, and each simulation was run between February 10 and the November 17. Fertilizer N use was $200 \mathrm{~kg} / \mathrm{ha}$ per year. Base milk price was set at 29 cents/L (c/L; 3.3\% protein and $3.6 \%$ fat). The insemination period lasted from April 20 to July 13. If not enough silage was generated on the farm, additional silage was purchased for $€ 175 / \mathrm{t}$ of DM, including all fixed and variable costs associated with silage production and including a utilization factor of $75 \%$ (Shalloo et al., 2004). All costs and prices included in the model were based on the most up-todate and relevant information available at the time of the simulation.

Sensitivity to milk price was tested at milk prices of $26 \mathrm{c} / \mathrm{L}$ and $32 \mathrm{c} / \mathrm{L}$, but milk price did not change the economic impact of any of the scenarios examining the utilization of SS; therefore, these data are not presented in this paper. This paper did not simulate genetic gain associated with the scenarios modeled, as the primary goal was to focus on the effect of the use of SS at different levels of herd phenotypic fertility performance, and genetic merit for fertility traits was used to create herds with divergent phenotypic fertility performance.

\section{RESULTS}

The main results of the simulation are presented in Tables 1 and 2. Table 3 presents the P/AI for inseminations with dairy and beef semen in cows and heifers in the different herd fertility levels, relative P/AI for $\mathrm{SS}$, and reproductive management strategies. Figure 1 presents the variation in profitability (within and between years) for the different scenarios investigated.

\section{CONV System}

As herd genetics for fertility reduced, the mean calving date of the herd was delayed from February 11 for the good fertility herd to February 15 and 17 for the average and poor fertility herds, respectively. The change in mean calving date was relatively small because if the farmer did not have 100 cows to calve, heifers were purchased that would calve at the start of the calving period to satisfy model assumptions. This may not always be feasible in practice, as pregnant heifers with an expected calving date at the start of the calving period may not be available, and would instead need to be replaced with later calving purchased animals (cows or heifers). Hence, the change in mean calving date as a consequence of having either an average or poor fertility herd would be greater. In seasonal-calving systems, a delay in mean calving date can lead to a decrease in farm profitability due to asynchrony between feed demand and the seasonal grass supply (Shalloo et al., 2014). The average replacement rate increased from $19 \%$ for the good fertility herd to $25 \%$ and $32 \%$ for the average and poor fertility herds, respectively. The average numbers of CONV straws used were 176 (81 dairy, 95 beef), 203 (99 dairy, 104 beef), and 227 (117 dairy, 110 beef) for the good, average, and poor fertility herds, respectively. Out of the 100 lactating cows, the total number in-calf at the end of the breeding period was 90, 83, and 74 for the good, average, and poor fertility herds, respectively. The net number of surplus gestating animals was $2,-2$, and -8 , respectively. Average standard milk production per lactation was $6,655 \mathrm{~kg}$ for the good fertility herd. The average and poor fertility herds produced 141 and $275 \mathrm{~kg}$ less milk per cow per lactation, respectively, due to the younger parity structure of the herds.

The average farm profit was €98,280 per year for the good fertility herd. The decrease in fertility reduced farm profit by approximately $10 \%$ for the average fertility herd (farm profit of $€ 88,506$ ) and $21 \%$ for the poor 
fertility herd (farm profit of $€ 77,956$ ) compared with the good fertility herd. The average insemination costs were $€ 3,259, € 3,818$, and $€ 4,344$ for the good, average, and poor fertility herds, respectively. Similarly, the value of nonreplacement calf sales was greater in good fertility herds $(€ 7,899)$ compared with average $(€ 7,345)$ and poor $(€ 6,599)$ fertility herds, respectively.

\section{S Simulations (85\% of Conventional)}

On average across all herd fertility levels, the S simulations resulted in mean calving date delayed by $1.8 \mathrm{~d}$, and the replacement rate increased by $0.8 \%$ (Table 1 ). The magnitude of the increase in the replacement rate reflected the fertility status of the herd $(+0.6 \%,+0.8 \%$, and $+1.1 \%$ for the good, average, and poor fertility herds, respectively). The small increase in replacement rate might seem surprising, but when looking at only the dairy AI events, P/AI decreased from $60 \%$ to $51 \%$ for the good fertility herds, $47 \%$ to $40 \%$ for the average fertility herds, and $37 \%$ to $31 \%$ for the poor fertility herds (Table 3). For the heifers, P/AI decreased from $74 \%$ to $63 \%$ for the good fertility herds, $69 \%$ to $59 \%$ for the average fertility herds, and $64 \%$ to $55 \%$ for the poor fertility herds. Those reductions are in line with the $85 \%$ relative $\mathrm{P} / \mathrm{AI}$ expected for SS. When looking at the entire herd and including all AI events, however, the utilization of SS on some dams led to a decrease in herd mean $\mathrm{P} / \mathrm{AI}$ from $64 \%$ to $61 \%$ for the good fertility herds, $52 \%$ to $50 \%$ for the average fertility herds and $44 \%$ to $42 \%$ for the poor fertility herds, which explains the small variation in replacement rate.

The average number of SS straws used was of 54,65 , and 77 , and the average number of beef semen straws used was 131, 146, and 158 for the good, average, and poor fertility herds, respectively. This resulted in 25,26 ,

Table 1. Effect of herd fertility level, relative pregnancy per AI (P/AI) for sexed semen and reproductive management strategies on the main reproduction outcome variables ${ }^{1}$

\begin{tabular}{|c|c|c|c|c|c|c|c|c|c|c|}
\hline $\begin{array}{l}\text { Herd } \\
\text { fertility }\end{array}$ & $\begin{array}{l}\text { Relative } \\
\mathrm{P} / \mathrm{AI}\end{array}$ & Strategy & $\begin{array}{l}\text { Mid } \\
\text { calving } \\
\text { date }\end{array}$ & $\begin{array}{l}\text { Replacement } \\
\text { rate }(\%)\end{array}$ & $\begin{array}{c}\text { Male dairy } \\
\text { calves } \\
\text { born (n) }\end{array}$ & $\begin{array}{c}\text { Female dairy } \\
\text { calves } \\
\text { born }(\mathrm{n})\end{array}$ & $\begin{array}{l}\text { Beef } \\
\text { calves } \\
\text { (n) }\end{array}$ & $\begin{array}{l}\text { Gestating } \\
\text { cows } \\
\text { (n) }\end{array}$ & $\begin{array}{l}\text { Gestating } \\
\text { heifer } \\
(\mathrm{n})\end{array}$ & $\begin{array}{l}\text { Net surplus } \\
\text { gestating } \\
\text { dams }^{2}(\mathrm{n})\end{array}$ \\
\hline \multirow[t]{7}{*}{ Good } & $\mathrm{CONV}$ & & 41.3 & 19.4 & 23 & 23 & 53 & 90 & 22 & 2 \\
\hline & \multirow{2}{*}{$100 \%$} & $\mathrm{~S}_{\mathrm{Sel}}$ & 40.2 & 20.4 & 3 & 25 & 71 & 90 & 23 & 4 \\
\hline & & $\mathrm{S}_{\text {Sunc }}$ & 34.9 & 21.1 & 3 & 25 & 72 & 91 & 24 & 5 \\
\hline & $85 \%$ & $\mathrm{~S}$ & 43.0 & 20.0 & 3 & 25 & 72 & 90 & 23 & 3 \\
\hline & \multirow[t]{3}{*}{$70 \%$} & S & 46.3 & 20.6 & 3 & 25 & 71 & 89 & 23 & 2 \\
\hline & & $\mathrm{S}_{\mathrm{Sel}}$ & 45.7 & 21.3 & 3 & 25 & 71 & 89 & 23 & 2 \\
\hline & & $\mathrm{S}_{\mathrm{S} \text { nnc }}$ & 38.3 & 21.1 & 3 & 24 & 72 & 91 & 23 & 4 \\
\hline \multirow[t]{5}{*}{ Average } & CONV & & 45.6 & 25.2 & 25 & 25 & 49 & 83 & 24 & -2 \\
\hline & \multirow[t]{3}{*}{$100 \%$} & $\mathrm{~S}$ & 45.3 & 25.2 & 4 & 26 & 69 & 83 & 24 & -2 \\
\hline & & $\mathrm{S}_{\mathrm{Sel}}$ & 45.1 & 25.3 & 4 & 26 & 69 & 83 & 24 & -2 \\
\hline & & $\mathrm{S}_{\text {Sync }}$ & 39.2 & 24.5 & 4 & 25 & 70 & 85 & 24 & 0 \\
\hline & $70 \%$ & $\mathrm{~S}_{\text {Sync }}$ & 41.9 & 24.9 & 4 & 25 & 70 & 84 & 23 & -1 \\
\hline \multirow[t]{10}{*}{ Poor } & $\mathrm{CONV}$ & & 47.7 & 32.0 & 27 & 28 & 44 & 74 & 26 & -8 \\
\hline & \multirow{3}{*}{$100 \%$} & $\mathrm{~S}$ & 47.7 & 31.9 & 6 & 28 & 65 & 75 & 25 & -7 \\
\hline & & $\mathrm{S}_{\mathrm{Sel}}$ & 47.7 & 32.0 & 6 & 28 & 65 & 75 & 26 & -7 \\
\hline & & $\mathrm{S}_{\mathrm{Sunc}}$ & 42.5 & 30.0 & 6 & 27 & 67 & 77 & 25 & -5 \\
\hline & \multirow[t]{3}{*}{$85 \%$} & S & 49.4 & 33.1 & 7 & 29 & 64 & 73 & 25 & -8 \\
\hline & & $\mathrm{S}_{\mathrm{Sel}}$ & 49.3 & 32.9 & 7 & 29 & 64 & 73 & 26 & -8 \\
\hline & & $\mathrm{S}_{\mathrm{Sunc}}$ & 43.4 & 30.3 & 6 & 27 & 66 & 77 & 25 & -6 \\
\hline & \multirow{3}{*}{$70 \%$} & $\mathrm{~S}^{\text {Syic }}$ & 52.0 & 34.7 & 8 & 29 & 62 & 71 & 26 & -10 \\
\hline & & $\mathrm{S}_{\mathrm{Sel}}$ & 51.4 & 34.5 & 8 & 29 & 62 & 72 & 26 & -10 \\
\hline & & $\mathrm{S}_{\mathrm{Sync}}$ & 44.3 & 30.6 & 6 & 26 & 67 & 76 & 25 & -7 \\
\hline
\end{tabular}

${ }^{1} \mathrm{CONV}=$ animals inseminated with nonsexed semen until 50 animals were pregnant; beef semen was used afterward. $\mathrm{S}=$ cows inseminated with sexed semen until 28 animals were pregnant; beef semen was used afterward. $\mathrm{S}_{\text {Sel }}=$ sexed semen was used only on animals with high predicted chance of successful conception (maximum of 28 animals pregnant with sexed semen); beef semen was used on other animals or after 28 pregnant animals were reached. $S_{\text {Sync }}=$ synchronization of animals with high predicted chance of successful conception and use of sexed semen (to reach 28 animals pregnant); beef semen was used afterward.

${ }^{2}$ Value on December $31 ; 10 \%$ of random culling was applied on gestating cows and $5 \%$ on gestating heifers. 
and 29 dairy heifer calves being born (plus 3, 5, and 7 male dairy calves). The increased number of dairy calf births and the greater proportion of male dairy calves with declining herd fertility was because any pregnant heifers that were purchased to maintain herd size were assumed to have been inseminated with CONV dairy breed semen. The number of beef calf births was 72, 69, and 64 for the good, average, and poor fertility herds, respectively. This represented an average increase in the number of beef calves born of 19,20 , and 20 calves compared with the CONV scenario for the good, average, and poor fertility herds, respectively. The average number of gestating cows at the end of the breeding season was 90,82 and 73 . There was a surplus of gestating animals (3) for the good fertility herd and a deficit of 3 and 8 for the average and poor fertility herd simulations, respectively.

The $\mathrm{S}$ simulation led to minimal change in profitability for the poor fertility herds $(-€ 52)$ but did lead to an increase in profitability for the average and the good fertility herds (€532 and €1,369; Table 2). The total costs for insemination were greater in the S simulation compared with the CONV simulation $(+€ 862$, $+€ 1,012$, and $+€ 1,177$ for the good, average, and poor fertility herds, respectively). The average revenue from calf sales was increased in the $\mathrm{S}$ simulations compared with the CONV simulations $(+€ 2,831,+€ 2,951$, and $+€ 2,959$ for the good, average, and poor fertility herds, respectively).

\section{$S_{\text {Sel }}$ Simulations (85\% of Conventional)}

On average, across all the herd fertility levels, the $\mathrm{S}_{\mathrm{Sel}}$ simulations resulted in the mean calving date being $1.6 \mathrm{~d}$ later and an increase in the replacement rate by $1.0 \%$ compared with the CONV simulations (Table 1 ). The $\mathrm{S}_{\mathrm{Sel}}$ led to a slightly greater replacement rate than the $\mathrm{S}$ simulation due to the fact that more heifers were inseminated with SS (average of +4.5 inseminations across all fertility levels) due to their greater probabil-

Table 2. Effect of herd fertility level, relative pregnancy per AI (P/AI) for sexed semen and reproductive management strategies on profitability and costs related to semen usage ${ }^{1}$

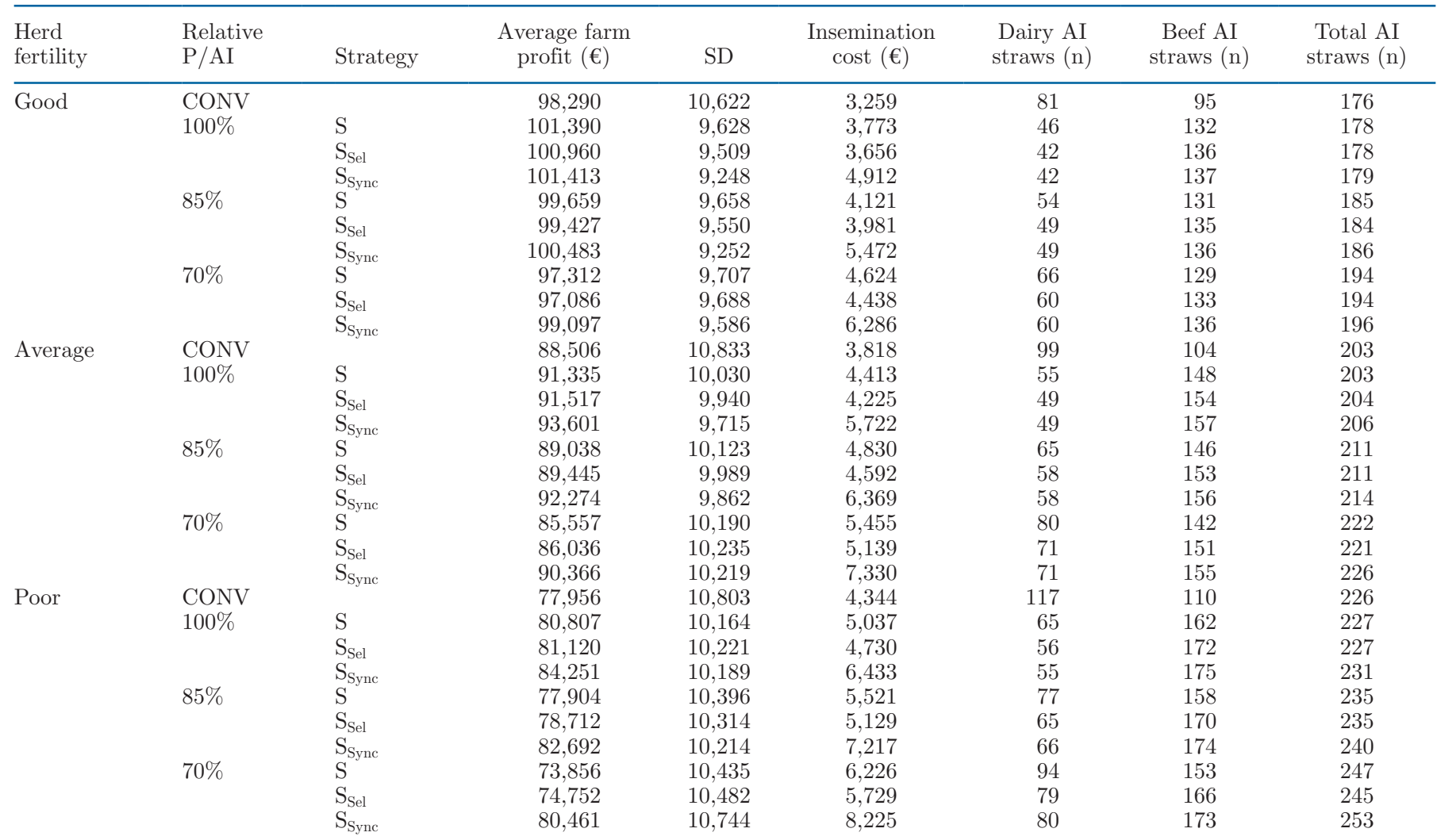

${ }^{1} \mathrm{CONV}=$ animals inseminated with nonsexed semen until 50 animals were pregnant; beef semen was used afterward. $\mathrm{S}=$ cows inseminated with sexed semen until 28 animals were pregnant; beef semen was used afterward. $\mathrm{S}_{\mathrm{Sel}}=$ sexed semen was used only on animals with high predicted chance of successful conception (maximum of 28 animals pregnant with sexed semen); beef semen was used on other animals or after 28 pregnant animals were reached. $\mathrm{S}_{\mathrm{Sync}}=$ synchronization of animals with high predicted chance of successful conception and use of sexed semen (to reach 28 animals pregnant); beef semen was used afterward. 
Table 3. Effect of herd fertility level, relative pregnancy per AI (P/AI) for sexed semen and reproductive management strategies on $\mathrm{P} / \mathrm{AI}$ for inseminations with dairy and beef breed semen straws ${ }^{1}$

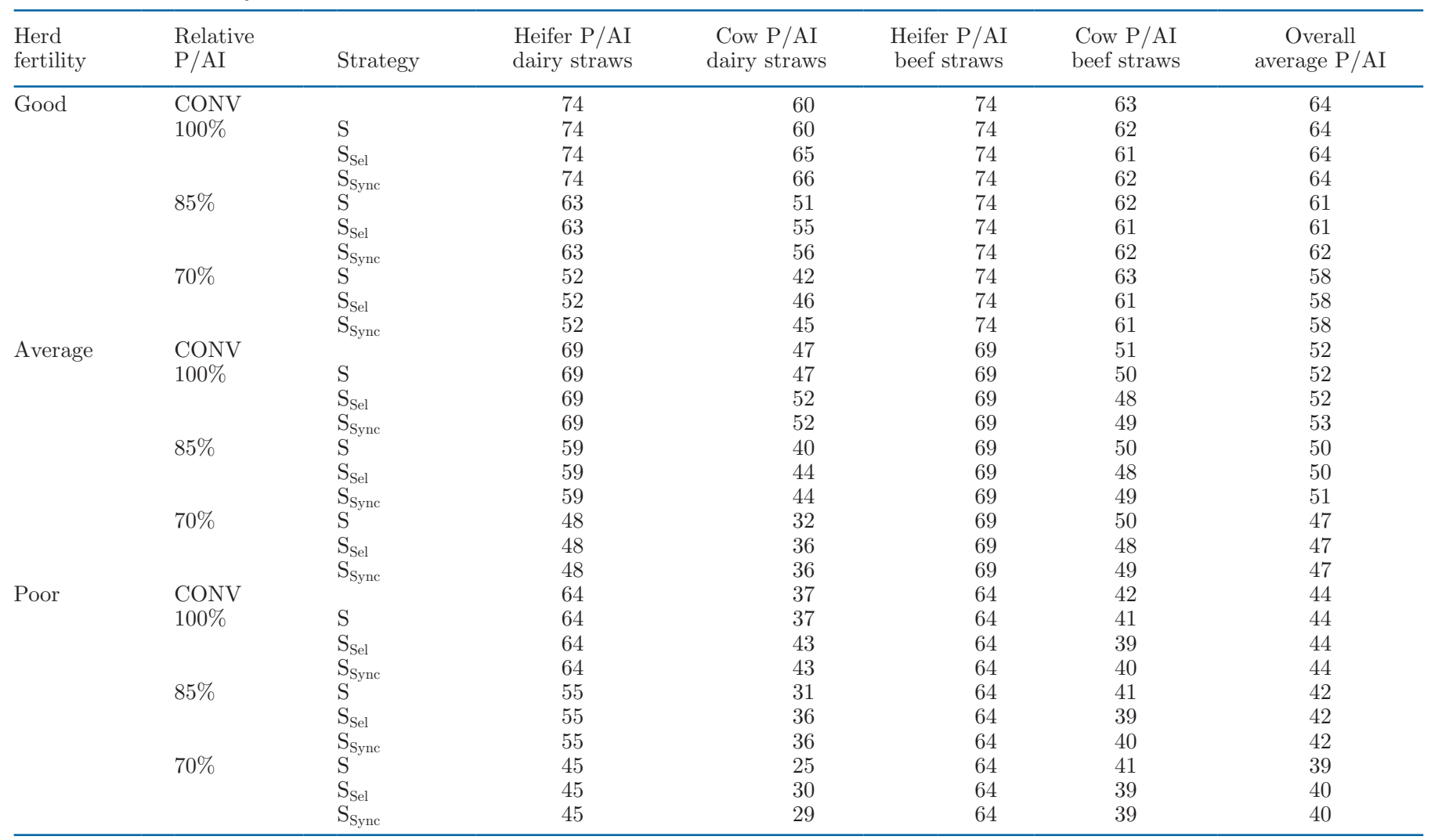

${ }^{1} \mathrm{CONV}=$ animals inseminated with nonsexed semen until 50 animals were pregnant; beef semen was used afterward. $\mathrm{S}=$ cows inseminated with sexed semen until 28 animals were pregnant; beef semen was used afterward. $\mathrm{S}_{\text {Sel }}=$ sexed semen was used only on animals with high predicted chance of successful conception (maximum of 28 animals pregnant with sexed semen); beef semen was used on other animals or after 28 pregnant animals were reached. $\mathrm{S}_{\text {Sync }}=$ synchronization of animals with high predicted chance of successful conception and use of sexed semen (to reach 28 animals pregnant); beef semen was used afterward.

ity of success. The strategy of choosing the best fertility cows for targeted usage of SS resulted in greater P/AI for the dairy inseminations on cows in the $\mathrm{S}_{\mathrm{Sel}}$ compared with the S simulation (average increase of $4.6 \%$ ), but consequently resulted in a small decrease in $\mathrm{P} /$ AI for the beef insemination on cows (average decrease of $1.6 \%$ ). Collectively, this resulted in similar overall herd percentage of success between the 2 insemination strategies (Table 3). The average number of SS straws used was 49, 58, and 65 for the good, average, and poor fertility herd simulations, respectively. This was 4,7 , and 12 less than for the $\mathrm{S}$ simulations. The average number of beef semen straws was 135, 153, and 170 for the good, average, and poor fertility herd simulations, respectively, which was greater than both the CONV simulations $(+39,+49$, and +60 , respectively $)$ and the $\mathrm{S}$ simulations $(+4,+7$, and +11 , respectively). This resulted in 71, 69, and 64 beef calves being born in the good, average, and poor fertility herd simulations, respectively. The average number of gestating cows at the end of the grazing season was 90, 82, and 73 animals for the good, average, and poor fertility herds, respectively. There was a surplus of gestating animals (3) for the good fertility herd and a deficit of 2 and 8 for the average and poor fertility herd simulations, respectively.

The $\mathrm{S}_{\mathrm{Sel}}$ simulations resulted in average farm profit that was similar to the CONV simulation. The insemination cost was greater in the $\mathrm{S}_{\mathrm{Sel}}$ simulations by $(+€ 1,138,+€ 940$, and $+€ 757$ for the good, average and poor fertility herds, respectively) when compared with the CONV simulations (Table 2). When compared with the $\mathrm{S}$ simulation, the $\mathrm{S}_{\mathrm{Sel}}$ strategy of selecting specific cows for SS usage led to a small decrease in farm profit for the good fertility herd simulation $(-€ 231)$, which was due to the small increase in replacement rate as more heifers were inseminated with SS due to their better fertility performance. For the average and poor fertility herd simulations, $S_{\text {Sel }}$ led to an increase in total farm profit compared with the $\mathrm{S}$ simulations $(+€ 408$ and $+€ 809$, respectively). The average revenue from 

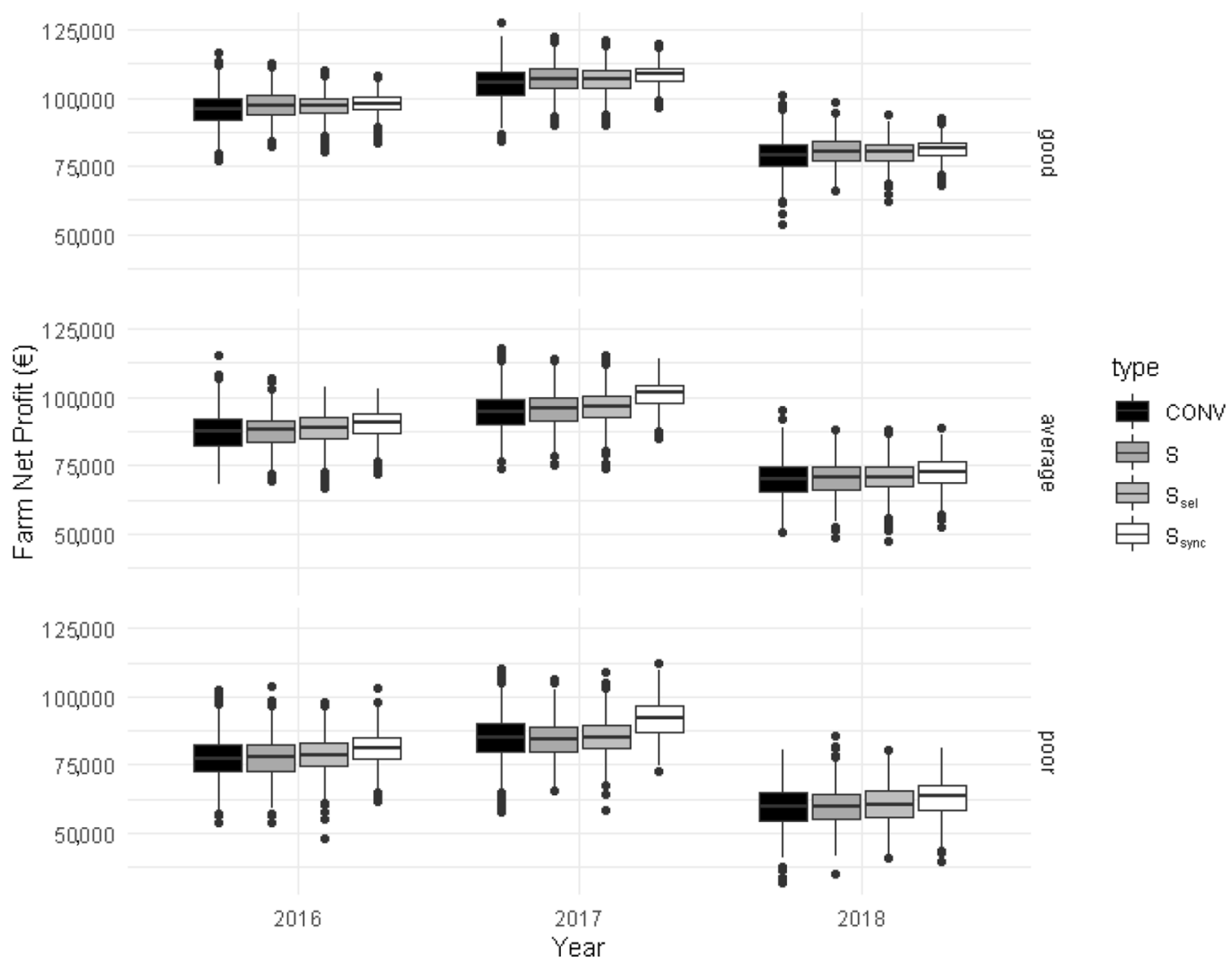

Figure 1. Variation in farm net profit (1,000 simulations) for the final $3 \mathrm{yr}$ of the simulations, depending on the type of insemination strategies and the fertility of the herd. CONV = animals inseminated with nonsexed semen until 50 animals were pregnant; beef semen was used afterward. S = cows inseminated with sexed semen until 28 animals were pregnant; beef semen was used afterward. $\mathrm{S}_{\mathrm{Sel}}=$ sexed semen was used only on animals with high predicted chance of successful conception (maximum of 28 animals pregnant with sexed semen); beef semen was used on other animals or after 28 pregnant animals were reached. $\mathrm{S}_{\mathrm{Sync}}=$ synchronization of animals with high predicted chance of successful conception and use of sexed semen (to reach 28 animals pregnant); beef semen was used afterward.

calf sales was greater in the $\mathrm{S}_{\mathrm{Sel}}$ simulations compared with the CONV simulation $(+€ 2,800,+€ 2,932$, and $+€ 2,950$ for the good, average, and poor fertility herds, respectively). When compared with the S simulations, the $\mathrm{S}_{\mathrm{Sel}}$ simulations led to a decrease in insemination costs of $-€ 141,-€ 238$, and $-€ 392$ due to the reduced number of SS straws used.

\section{$S_{\text {Sync }}$ Simulations (85\% of Conventional)}

On average, across all the herd fertility levels, $\mathrm{S}_{\text {Sync }}$ resulted in an earlier mean calving day by $4.8 \mathrm{~d}$ compared with the CONV simulations, and the average replacement rate was exactly the same. When looking at the different fertility levels, however, the $\mathrm{S}_{\mathrm{Sync}}$ simulations resulted in a $1.6 \%$ increase in the replacement rate for the good fertility herds and a decrease of $1.7 \%$ for the poor fertility herds compared with the CONV simulation. This was due to the fact that for the poor fertility herds, synchronizing the first insemination allowed time for more chances for the animal to be reinseminated during the breeding season, increasing the total number of cows in gestation at the end of the insemination period (increase of 3 gestating cows). The increase for the good fertility herd in replacement rate was due to the fact that when synchronized, some priority was given to heifers over cows as they had a higher $\mathrm{P} / \mathrm{AI}$, leading to more heifers coming into the herd.

The average number of beef semen straws used was 136, 156, and 174 for the good, average, and poor herd fertility simulations, which resulted in 72,70 , and 66 beef calves sold, respectively. There was a surplus of gestating animals (5) for the good fertility herd and a deficit of 1 and 6 for the average and poor herd fertility simulations, respectively.

Across all levels of herd fertility, the $\mathrm{S}_{\text {Sync }}$ simulations had greater farm profit compared with the CONV simulations $(+€ 2,194,+€ 3,768$, and $+€ 4,736$ for the good, average, and poor fertility herds, respectively). 
The cost of hormone treatments per farm was $€ 1,479$, $€ 1,736$, and $€ 1,983$ for the good, average, and poor fertility herd simulations, respectively. The increase in the cost of insemination (taking into account the hormonal treatment) for the $S_{\text {Sync }}$ simulations was $+€ 2,213$, $+€ 2,551$, and $+€ 2,872$ compared with the CONV simulations, and $+€ 1,492,+€ 1,777$, and $+€ 2,087$ compared with the $\mathrm{S}_{\mathrm{Sel}}$ for the good, average, and poor fertility herds, respectively. The average revenue from nonreplacement calf sales was greater than CONV $(+€ 2,855$, $+€ 3,159$, and $+€ 3,354)$ and $\mathrm{S}_{\mathrm{Sel}}(+€ 55,+€ 226$, and $+€ 404)$ for the good, average, and poor fertility herds, respectively.

\section{Effect of the Variation in P/AI of SS}

Overall, if the relative P/AI with SS was $70 \%$ or less of CONV, the $\mathrm{S}$ and $\mathrm{S}_{\mathrm{Sel}}$ scenarios had poorer farm profitability compared with using CONV, whereas the $\mathrm{S}_{\text {Sync }}$ scenario still had a greater farm profit $(-€ 2,675$, $-€ 2,292$, and $+€ 1,725$ for the $\mathrm{S}, \mathrm{S}_{\mathrm{Sel}}$, and $\mathrm{S}_{\mathrm{Sync}}$, respectively, averaged across all herd fertility simulations; Table 2). A decrease in farm net profit was expected with poorer $\mathrm{P} / \mathrm{AI}$ arising from SS usage, and hence the increase in farm net profit for the $\mathrm{S}_{\mathrm{Sync}}$ simulation could appear surprising. Despite a large reduction in $\mathrm{P} / \mathrm{AI}$ for the dairy inseminations at $70 \%$ relative $\mathrm{P} /$ $\mathrm{AI}$, the replacement rate stayed the same between the $\mathrm{CONV}$ and $\mathrm{S}_{\text {Sync }}$. Furthermore, the actual number of cows in gestation at the end of the insemination period was greater (1.6 cows more) in the $\mathrm{S}_{\mathrm{Sync}}$ simulation compared with the CONV simulation due to earlier submission for AI on mating start date and allowing cows that were not pregnant after the first insemination more opportunities to return to estrus and get inseminated again. In addition, an earlier mean calving date (average of $4 \mathrm{~d}$ earlier) led to this slight increase in farm profit, despite the increased insemination cost compared with the CONV simulations.

Conversely, if the relative P/AI with SS was $100 \%$ of CONV, the use of SS always resulted in an increase in farm profitability compared with CONV $(+€ 1,521$, $+€ 1,910$, and $+€ 2,743$ for the $\mathrm{S}, \mathrm{S}_{\mathrm{Sel}}$, and $\mathrm{S}_{\mathrm{Sync}}$, respectively, averaged across all herd fertility simulations).

\section{Yearly Scenario Variations}

On average, the interannual variation measured by standard deviation represented $11.4 \%$ of the total net profit (considering only variation in weather and its effect on grass growth). This ranged from $9.1 \%$ for the good fertility herd $\mathrm{S}_{\text {Sync }}$ simulation at $100 \%$ relative $\mathrm{P} / \mathrm{AI}$ with SS to $14.1 \%$ for the poor fertility herd
$\mathrm{S}$ simulation at $70 \%$ relative $\mathrm{P} / \mathrm{AI}$ with $\mathrm{SS}$. Overall, increasing the level of herd fertility decreased the percentage variation in farm net profit, and apart from the $70 \%$ relative $\mathrm{P} / \mathrm{AI}$ simulations, the use of $\mathrm{SS}$ also reduced the percentage variation (Figure 1). This was due to the greater effect of randomness in the sex of the offspring derived from dairy AI in the CONV simulations, increasing the chance of having an inadequate number of female dairy calves in a given year. Figure 1 illustrates the variability between years in farm net profit for the different simulations. The variability for each year was partially dependent on the "luck" of insemination outcomes (pregnancy: 0 or 1; calf sex: male or female). Figure 1 also highlights the effect of a year with poor grass growth; for example, adverse weather conditions in Ireland in 2018 reduced farm profitability for all herds regardless of their fertility level and reproductive management strategies.

\section{DISCUSSION}

In seasonal-calving systems, excellent fertility is critical to keep the replacement rate low and also ensuring the synchrony of feed supply and feed demand (Shalloo et al., 2014). This is fundamentally different to indoor systems, where the seasonal variation in diet and feed availability is less pronounced if present at all. This study has highlighted the effect of herd fertility performance on profitability of dairy farms. The costs included in this study do not include hidden factors such as increased labor costs, reduced potential for expansion, or reduced realization of genetic gain. For herds that are achieving suboptimal fertility performance (e.g., average or poor fertility herds simulated in the current study), the focus should be on first improving fertility before other considerations are made regarding incorporating use of SS.

An improvement in herd phenotypic fertility performance could come from either improving the genetic merit for fertility traits in the herd or improved fertility management such as optimal BCS and energy balance at insemination (Cutullic et al., 2012). There is clearly large potential to increase profitability through improving herd fertility. Several studies have shown links between herd fertility and profitability (González-Recio et al., 2004; Shalloo et al., 2014). The costs associated with infertility in dairy herds can be broadly divided into the following 4 main categories: (1) longer calving intervals, (2) increased culling, (3) increased labor costs, and (4) increased costs associated with additional AI usage and interventions of one form or another. These costs were highlighted by Boichard (1990) when he highlighted additional inseminations, veterinary and hormonal costs, 
and a modification of current and subsequent lactations associated with infertility costs. In addition to these costs, which can be directly linked to infertility, there are indirect costs that can have significant implications for a dairy farm. These include reduced potential for herd expansion, and an increased likelihood of animals being purchased onto the farm, and thus presenting a biosecurity risk.

In dairy herds that use conventional dairy semen, male dairy calves are born in a large surplus. In the current study, when SS was used in a stable herd size scenario of 100 cows, we observed that the selective use of SS (at $85 \%$ relative $\mathrm{P} / \mathrm{AI}$ ) on heifers and targeted cows led to a slight increase in the farm profitability with $\left(\mathrm{S}_{\mathrm{Sync}}\right)$ or without $\left(\mathrm{S}_{\mathrm{Sel}}\right)$ use of synchronization. The increased sale value of the beef calves more than compensated for the increased insemination costs, even when coupled with a reduction in P/AI. Synchronization led to a further increase in farm profit for herds with average or poor fertility (equal profitability for the good fertility herd) due to the further increase in beef calf sales and an earlier mean calving date. In compact seasonal-calving systems, an earlier mean calving date means that a greater proportion of the herd are at least 42 DIM when the breeding season starts, and hence have had more time for uterine repair and resumption of estrous cyclicity. This results in a greater chance of both submission and conception at the start of the breeding period (Murphy et al., 2016). Herds are also more likely to have a longer lactation, as dry off is often conducted on a fixed calendar date in seasonal-calving systems.

As previously reported by (Maicas et al., 2020), the effect of a reduction in herd fertility due to SS usage is not homogeneous across herds. For example, some bulls had no decrease in $\mathrm{P} / \mathrm{AI}$ after sorting, whereas others had a marked reduction (Maicas et al., 2019, 2020). Similar observations have been reported for cows; cow fertility index, DIM at AI, BCS, and parity have strong influences on $\mathrm{P} / \mathrm{AI}$ for both CONV and SS (Maicas et al., 2019). Furthermore, there is some evidence of an AI technician effect (Healy et al., 2013; Drake et al., 2020), implying that how the SS straws are handled at the time of AI has a large effect on the chance of successful pregnancy establishment.

A limitation of the current study was that it did not take into account any genetic gain through simulations of the study or variation in genetics within the herd. This choice was made because the overall objective was to highlight the effects of different strategies for incorporating SS use in herds with different levels of phenotypic fertility performance. In the current study, divergent levels of herd phenotypic fertility performance were simulated using different cut-offs for the PTA values for fertility traits, but in reality, the reasons for differences between herds in phenotypic fertility performance are multifactorial (e.g., genetics, general husbandry, nutrition, health status). The incorporation of genetic gain in the current study could have led to phenotypic fertility performance converging in the different herds, which would have removed the fertility effects and made it impossible to ascertain the interaction of fertility and SS technologies. Although genetic gain was not simulated, it would be expected that the rate of genetic progress could be increased through targeting the usage of elite dairy bull genetics with the best dams in the herd, leading to faster genetic gain, and thus further profit gains in the $\mathrm{S}_{\mathrm{Sel}}$ and $\mathrm{S}_{\mathrm{Sync}}$ scenarios. The most fertile animals will establish pregnancy at the start of the breeding period, and will hence calve at the start of the calving season. Using SS on targeted dams with the best EBI and excellent (predicted) fertility at the start of the breeding season would generate replacement heifers with superior EBI that enter the lactating herd $2 \mathrm{yr}$ later. Therefore, the rate of genetic progress in the herd as a whole increases.

More importantly, SS could create an opportunity for beef farmers. The profitability of dairy calf to beef systems is greater than suckler beef systems (i.e., a beef cow produces a calf and the calf suckles on the cow until weaning). Therefore, increasing the proportion of beef derived from the dairy herd will increase profitability in the beef sector. The use of dairy SS to generate replacements combined with beef breed AI (or natural service beef breed bull) to generate nonreplacements would lead to a marked increase in the beef merit of the calves derived from the dairy herd. The generation of nonreplacement calves with better beef merit from dairy dams that are not suitable to generate replacements will help facilitate this process. Within the last decade, SS has become an important tool to reduce the numbers of low value male dairy calves, and improve the social sustainability and consumer image of the dairy industry. There is also potential to improve the environmental credentials of the beef industry due to the potential to reduce the number of suckler cows (Holden and Butler, 2018). If beef-cross calves derived from the dairy herd displace commercial (nonpedigree) suckler beef production, it could help individual countries to reduce the environmental footprint of ruminant production (Mazzetto et al., 2020; van Selm et al., 2021). Furthermore, a recent analysis of land use in Ireland indicated that dairy beef has the potential to increase the overall efficiency of how land is used (Hennessy, Teagasc, Fermoy, Ireland, personal communication), increasing the quantities of human edible protein 
produced compared with a different system or enterprise. It is important to acknowledge that if the number of beef-cross calves was to markedly increase because of greater use of SS, the $€ 150$ difference in value between a male dairy calf and a beef-cross calf could be reduced, reducing the profitability of SS scenarios. Nevertheless, the market is currently far from being saturated with beef-cross calves, and reducing the number of male dairy calves is a more pressing issue.

\section{CONCLUSIONS}

This study highlighted that regardless of herd fertility, appropriate use of SS resulted in a slight increase in farm profitability and also simultaneously induced changes that improve the consumer perception of dairy farming. The use of synchronization and targeting the best dams for AI with SS would be a useful strategy to mitigate risk of poor $\mathrm{P} / \mathrm{AI}$. The use of SS has significant potential to help drive the integration between the dairy and beef herds if used correctly. The added advantage of increased genetic gain has the potential to further increase the potential of SS to deliver increased profitability in the future.

\section{ACKNOWLEDGMENTS}

Funding from the Irish Department of Agriculture, Food and the Marine STIMULUS research grant MULTIREPRO (15/S/696; Dublin, Ireland) is greatly appreciated, as well as a research grant from Science Foundation Ireland and the Department of Agriculture, Food and the Marine on behalf of the Government of Ireland under the grant 16/RC/3835 (VistaMilk; Dublin, Ireland). We are also grateful for the funding provided by the Irish Dairy Levy Trust (Dublin, Ireland). The authors have not stated any conflicts of interest.

\section{REFERENCES}

Boichard, D. 1990. Estimation of the economic value of conception rate in dairy cattle. Livest. Prod. Sci. 24:187-204. https://doi.org/ 10.1016/0301-6226(90)90001-M.

Butler, S. T., I. Hutchinson, A. Cromie, and L. Shalloo. 2014. Applications and cost benefits of sexed semen in pasture-based dairy production systems. Animal 8(Suppl. 1):165-172. https://doi.org/ 10.1017/S1751731114000664.

Cutullic, E., L. Delaby, Y. Gallard, and C. Disenhaus. 2011. Towards a better understanding of the respective effects of milk yield and body condition dynamics on reproduction in Holstein dairy cows. Animal 6:476-487. https://doi.org/10.1017/S175173111100173X.

Drake, E., S. Holden, V. Aublet, R. Doyle, C. Millar, S. Moore, C. Maicas, F. Randi, A. Cromie, P. Lonergan, and S. T. Butler. 2020. Evaluation of delayed timing of artificial insemination with sex-sorted sperm on pregnancy per artificial insemination in seasonal-calving, pasture-based lactating dairy cows. J. Dairy Sci. 103:12059-12068. https://doi.org/10.3168/jds.2020-18847.
Garner, D. L., B. Gledhill, D. Pinkel, S. Lake, D. Stephenson, M. Van Dilla, and L. Johnson. 1983. Quantification of the X-and Ychromosome-bearing spermatozoa of domestic animals by flow cytometry. Biol. Reprod. 28:312-321. https://doi.org/10.1095/ biolreprod28.2.312.

González-Recio, O., M. Pérez-Cabal, and R. Alenda. 2004. Economic value of female fertility and its relationship with profit in Spanish dairy cattle. J. Dairy Sci. 87:3053-3061. https://doi.org/10.3168/ jds.S0022-0302(04)73438-4.

Healy, A. A., J. House, and P. Thomson. 2013. Artificial insemination field data on the use of sexed and conventional semen in nulliparous Holstein heifers. J. Dairy Sci. 96:1905-1914. https://doi.org/ $10.3168 /$ jds.2012-5465.

Holden, S. A., and S. Butler. 2018. Review: Applications and benefits of sexed semen in dairy and beef herds. Animal 12:s97-s103. https: //doi.org/10.1017/S1751731118000721.

Hutchinson, I. A., L. Shalloo, and S. Butler. 2013a. Expanding the dairy herd in pasture-based systems: The role of sexed semen use in virgin heifers and lactating cows. J. Dairy Sci. 96:6742-6752. https://doi.org/10.3168/jds.2012-6476.

Hutchinson, I. A., L. Shalloo, and S. Butler. 2013b. Expanding the dairy herd in pasture-based systems: The role for sexed semen use on virgin heifers. J. Dairy Sci. 96:1312-1322. https://doi.org/10 $.3168 /$ jds.2012-6126.

ICBF. 2017. What is EBI? Accessed Jan. 13, 2021. https://www.icbf .com/wp/?p=5772.

ICBF. 2018. Update to Economic Values in the EBI. Accessed Jan. 13 , 2021. https://www.icbf.com/wp/?p=9695.

Macmillan, K. 2002. Advances in bovine theriogenology in New Zealand. 1. Pregnancy, parturition and the postpartum period. N. Z. Vet. J. 50(sup3):67-73.

Maicas, C., S. Holden, E. Drake, A. Cromie, P. Lonergan, and S. Butler. 2020. Fertility of frozen sex-sorted sperm at $4 \times 106$ sperm per dose in lactating dairy cows in seasonal-calving pasture-based herds. J. Dairy Sci. 103:929-939. https://doi.org/10.3168/jds.2019 $-17131$.

Maicas, C., I. Hutchinson, J. Kenneally, J. Grant, A. Cromie, P. Lonergan, and S. Butler. 2019. Fertility of fresh and frozen sex-sorted semen in dairy cows and heifers in seasonal-calving pasture-based herds. J. Dairy Sci. 102:10530-10542. https://doi.org/10.3168/jds 2019-16740.

Mazzetto, A. M., G. Bishop, D. Styles, C. Arndt, R. Brook, and D. Chadwick. 2020. Comparing the environmental efficiency of milk and beef production through life cycle assessment of interconnected cattle systems. J. Clean. Prod. 277:124108. https://doi.org/10 .1016/j.jclepro.2020.124108

McDonald, R., L. Shalloo, K. Pierce, and B. Horan. 2013. Evaluating expansion strategies for startup European Union dairy farm businesses. J. Dairy Sci. 96:4059-4069. https://doi.org/10.3168/ jds.2012-6365.

McEvoy, M., M. O'Donovan, and L. Shalloo. 2011. Development and application of an economic ranking index for perennial ryegrass cultivars. J. Dairy Sci. 94:1627-1639. https://doi.org/10.3168/jds .2010-3322.

Murphy, C., L. Shalloo, I. Hutchinson, and S. Butler. 2016. Expanding the dairy herd in pasture-based systems: The role of sexed semen within alternative breeding strategies. J. Dairy Sci. 99:6680-6692. https://doi.org/10.3168/jds.2015-10378.

Oikawa, K., T. Yamazaki, S. Yamaguchi, H. Abe, H. Bai, M. Takahashi, and M. Kawahara. 2019. Effects of use of conventional and sexed semen on the conception rate in heifers: A comparison study. Theriogenology 135:33-37. https://doi.org/10.1016/j .theriogenology.2019.06.012.

Ruelle, E., L. Delaby, and L. Shalloo. 2019. Linkage between predictive transmitting ability of a genetic index, potential milk production, and a dynamic model. J. Dairy Sci. 102:3512-3522. https://doi .org/10.3168/jds.2018-15197.

Ruelle, E., L. Delaby, M. Wallace, and L. Shalloo. 2016. Development and evaluation of the herd dynamic milk model with focus on the individual cow component. Animal 10:1986-1997. https://doi.org/ $10.1017 /$ S1751731116001026. 
Ruelle, E., D. Hennessy, and L. Delaby. 2018. Development of the Moorepark St Gilles grass growth model (MoSt GG model): A predictive model for grass growth for pasture based systems. Eur. J. Agron. 99:80-91. https://doi.org/10.1016/j.eja.2018.06.010.

Ruelle, E., L. Shalloo, M. Wallace, and L. Delaby. 2015. Development and evaluation of the pasture-based herd dynamic milk (PBHDM) model for dairy systems. Eur. J. Agron. 71:106-114. https://doi .org/10.1016/j.eja.2015.09.003.

Shalloo, L., A. Cromie, and N. McHugh. 2014. Effect of fertility on the economics of pasture-based dairy systems. Animal 8(s1):222-231.

Shalloo, L., P. Dillon, M. Rath, and M. Wallace. 2004. Description and validation of the Moorepark Dairy system model. J. Dairy Sci. 87:1945-1959. https://doi.org/10.3168/jds.S0022-0302(04)73353 $-6$.

van Selm, B., I. J. de Boer, S. F. Ledgard, and C. E. van Middelaar. 2021. Reducing greenhouse gas emissions of New Zealand beef through better integration of dairy and beef production. Agric. Syst. 186:102936. https://doi.org/10.1016/j.agsy.2020.102936.
Veerkamp, R. F., P. Dillon, E. Kelly, A. R. Cromie, and A. F. Groen. 2002. Dairy cattle breeding objectives combining yield, survival and calving interval for pasture-based systems in Ireland under different milk quota scenarios. Livest. Prod. Sci. 76:137-151. https: //doi.org/10.1016/S0301-6226(02)00006-4.

Vishwanath, R., and J. Moreno. 2018. Semen sexing-current state of the art with emphasis on bovine species. Animal 12(s1):s85-s96. https://doi.org/10.1017/S1751731118000496.

\section{ORCIDS}

E. Ruelle (ㄴ) https://orcid.org/0000-0003-0077-8106

L. Shalloo ๑ https://orcid.org/0000-0003-1714-672X

S. T. Butler (1) https://orcid.org/0000-0003-1542-8344 